\title{
An Assessment of the Causes of Tick Resistance to Acaricides use on Cattle in kazo County Kiruhura District, Uganda
}

\author{
Boniface Nzuve Wambua \\ University of Nairobi \\ Department of Geography and Environmental Studies \\ P.O Box 3019700100 Nairobi - Kenya \\ Edward Muhigirwa \\ Eastern and Southern Africa Institute of Management (ESAMI) \\ Business School \\ P.O Box 3030, Arusha - Tanzania
}

\begin{abstract}
Tick resistance to acaricides has become a major problem to Uganda's livestock industry. Control of ticks requires the use of appropriate chemicals administered through most efficient methods. This paper focused on 'assessing the causes of tick resistance to use of acaricides on cattle in Uganda, Kazo County in Kiruhura District.' Participants targeted included: farmers, veterinary professionals, retail drug shops, suppliers and or importers of veterinary medicines thus giving a sample size of 125 respondents. Purposive and systematic sampling procedures were used to select the respondents. The data collection procedures used included: questionnaires and interviews, observations, and document review. The study findings shows that Acaricides are available and all farmers have access to them but the accessibility is however undermined by the price of acaricides, distance travelled to reach the drug shop, and use of inadequate methods for tick control thus culminating to tick resistance in use of acaricides. The inadequate regulatory framework exposes the farmer to adulterated acaricides instead of the original chemicals which has further enhanced tick resistance to acaricides. The study concludes that tick resistance to acaricides remains a challenge to management of cattle diseases in Kiruhura District due to inadequate regulation in the veterinary pharmaceutical sector which has resulted in penetration of adulterated acaricides in the market, use of outdated Essential Drug List (EDL) by stockists and influence of market forces of demand and supply. Subsequently, the paper recommends farmers to adopt the recommended Good Agricultural practices(GAP) since they result in reduced farm risks and expenses, Uganda government to increase farmers' access to professional advice by recruitment and deployment of staff at the lower levels and further scientific research be done on the efficacy of acaricides for tick control.
\end{abstract}

Key words: Tick resistance, Acaricides Chemicals

\subsection{Introduction}

\subsection{Background study}

The most common method to control ticks is use of different types of chemical acaricides which are used in different method of applications such as hand dressing, spraying, spray races, systemic and dipping (McLeod et al, 1995). The prolonged incorrect use of acaricides may cause resistance in ticks against acaricides (Whitehead, 1973). The resistance can be caused by a numbers of mechanisms and when resistant ticks survive, they pass this ability by genetic to their offspring. The higher reproductive rate of ticks that have heritable resistance factors will result to increase in proportion of population of ticks that carry genes of acaricides resistance (Whitehead, 1973).

Ticks, generally regarded as the ectoparasites that cause the greatest economic losses to livestock production in the world today particularly in the Tropics, adversely affect livestock hosts in several ways (Snelson, 1975): they contribute to unthriftiness and anaemia by exsanguination; they damage hides and subject livestock to secondary infection; they cause toxicoses and paralysis by the injection of their salivary secretions; and, most importantly, they transmit pathogenic agents that cause diseases, many of which result in debility and death. Of the many tick-borne livestock diseases, five are of particular concern: East Coast Fever, bovine anaplasmosis, bovine babesioses, theilerioses, and heart water. The economic impact of ticks and the diseases they transmit is enormous. Not only is the annual global cost of ticks and tick-borne diseases estimated to run to thousands of millions of dollars, but also mankind is deprived of a significant amount of animal protein that cannot be replaced from other sources (Bram, 1975; Callow, 1975; Drummond et al. 1978; Snelson, 1975). 
The livestock population of Uganda consists of 13 million cattle. Tick borne diseases and Trypanosomiasis are among the major diseases caused by ticks and tsetse flies whose control requires use of chemicals. The control of these vectors reduce the incidence of diseases and improves animal production. These chemicals are mainly referred to as Acaricides in Veterinary. Over $90 \%$ of the cattle are owned by smallholder farmers and graze communally. Livestock production contributes $16 \%$ of the total gross domestic production in form of milk and meat as a sub-sector of agricultural production in Uganda. About a third of the 2.5 million farming households depend on livestock for a major part of their income.

Ticks and tick-borne diseases (T\&TBDs) are important health impediment to the improvement \& development of livestock industry in Uganda due to the high economic costs (losses) they impose on farmers and national economies. Application of acaricides for tick control should therefore be done using the right concentrations during spaying of ticks on the farms. Low/poor concentrations are not effective on tick control and this reduces farm productivity in terms of the quality and quantity of the beef/ diary production. On the other hand, the health of the famer and clients are at risk as there are chances of contracting diseases resulting from exposure to chemicals during application, and contamination of the animal products respectively. Productivity of the population is lowered in the event of ill health resulting from inhaling and consumption of contaminated air and animal products, which in turn affects the overall population's contribution towards the country's Gross Domestic Product (GDP).

To counteract the adverse effects of ticks and tick-borne diseases, a variety of tick-control programmes have been integrated into modern livestock management practices. Foremost among these is chemical tick-control, which not only decreases the detrimental effects of the ticks themselves, but also interrupts the transmission cycle of pathogenic agents and, thus, reduces the incidence of tick-borne diseases. Depending on the tick species involved, the livestockmanagement practices followed, the tick-borne diseases present, and the environmental conditions of an area, cattle are treated at periodical intervals with any one of over 30 available acaricide brands. The frequency of acaricide treatment may vary from every 3, 4 or 7 days in East Africa for the protection of cattle against ticks and tsetse flies. In addition to the chemical control of ticks, increased efforts are being made to introduce tick-resistant breeds of livestock that, though they continue to support tick populations, are not conducive to massive tick infestations. The control of tickborne diseases is also accomplished by the use of live, attenuated vaccines (Callow, 1978).

\subsection{Significance of the Study}

Cattle farming boost the welfare of farmers and contribute towards the GDP of Uganda. Eradication/control of ticks will increase the market for cattle products (diary, beef) resulting from the improved quality which shall as well increase the incomes of the farmers. With improved incomes, farmers shall be in better position to meet their domestic needs

Besides, the research is expected to benefit the academia by adding to the body of knowledge in the area of managing tick resistance to acaricides; as well as to add on to the data bank for research resources for the Institute as a point of reference for similar studies.

The data generated from this research is going to be used for decision-making as to which acaricides are the most effective in terms of; economic cost, control of ticks, safety in regard to general health of the population especially who consume beef/ and dairy products as well as environmental sustainability. This should enhance policy formulation on how to control ticks and tick-borne diseases.

\subsection{Scope of the Study}

The study was limited to an assessment of the causes of tick resistance to acaricides in Uganda; a case study of Kazo County in Kiruhura District. It focused on the content, geographical and time scope or the period that the researcher focused on for the study. The study content was limited to the 'effectiveness of acaricides' as the independent variable; 'Regulatory mechanisms' as the moderator variable; and 'Reduced tick resistance' as the dependent variable.

\section{4 conceptual framework}

In the context of this study, the "Effectiveness of Acaricides" was conceptualized as the Independent Variable (IV) and operationalized as: Types of acaricide used; Time of application; Frequency of application; Treat tick habitat only; Assured quality of acaricides; Toxicity; Affordability (price); and Availability. "Regulatory Mechanisms" was conceptualized as Moderator Variable (MV) and operationalized as Patent laws; licensing of acaricide outlets; Registration of acaricides; and Control of acaricide imports. The IV and MV determined "Tick Resistance" which is conceptualized as the Dependent Variable (DV) of this study and operationalized as; Improved Health of Cattle, Increased Economic Value, and Improved Quality of Cattle, as illustrated below; 


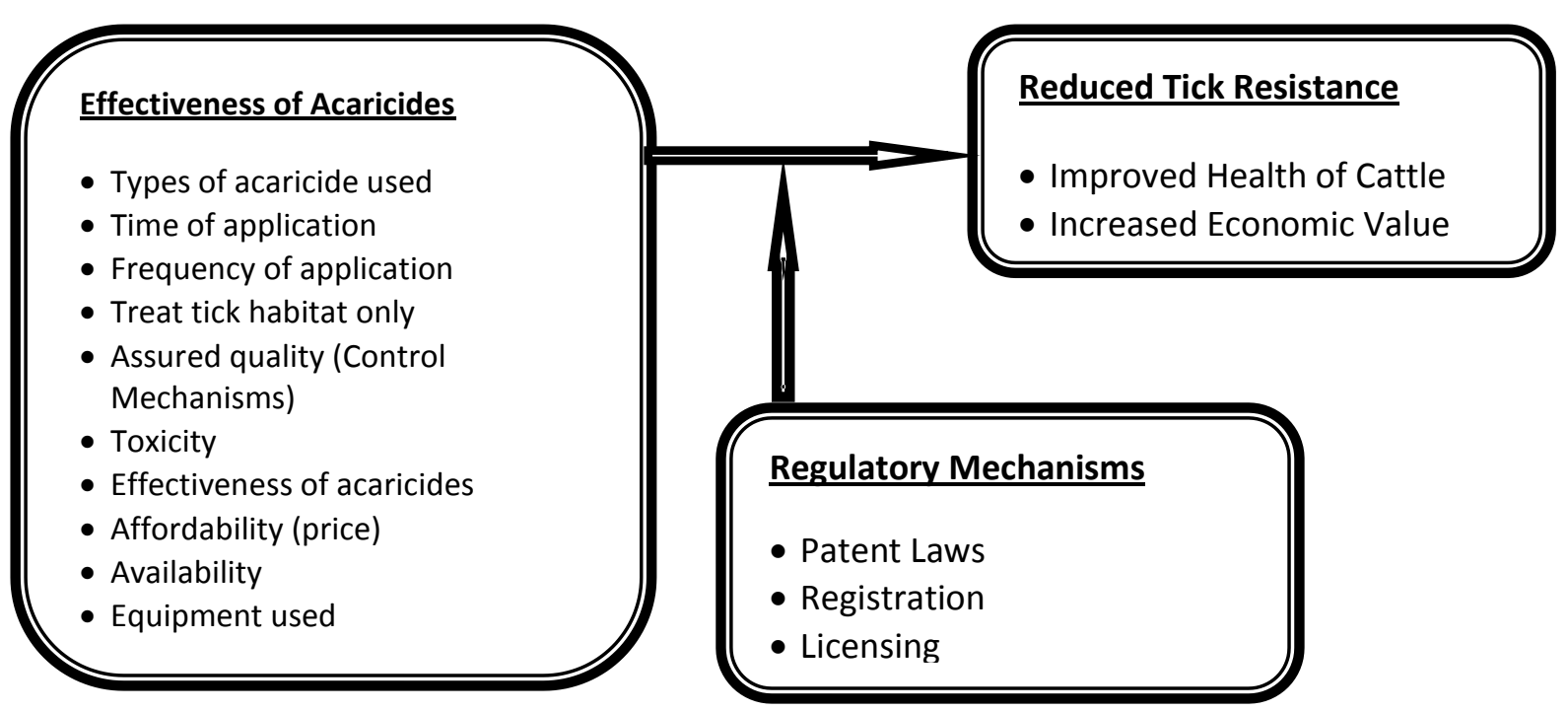

Source: Andersen R. \& Newman, J.F. (1973

\subsection{Summary of Literature}

It is evident from literature review that although several measures have been extensively utilized to control ticks in livestock (Cattle) production systems, there is need to explore more efficient approaches to completely eradicate ticks and tick-borne diseases. Tick had become resistant to synthetic pyrethroids and farmers reverted to using acaricides but the ticks were not dying yet they were losing animals at a high rate. Tick control is treatment that reduces exposure of livestock to the target ticks within a specific area and time. All eradications and most controls of ticks are intended to protect livestock yet this would call for more integrated approaches in this intervention. The global costs of tick and tick-borne disease control remains high making efforts to increase output of animal products and improving productivity futile. In Uganda, the consequence is very bad as ticks are responsible for almost the $90 \%$ of the cattle deaths. Despite this observation, inadequate studies have been conducted in the study area to determine the causes of tick resistance to the recommended chemicals

The availability of adequate acaricides to kill ticks in the face of multi-resistant tick strains is hampered by escalating complexity and cost of new classes of chemical. The delay to adjust to more efficient acaricides suggests that tick species is likely to be adapted to a distinct cycle of even more resistance. Chemical acaricides, if correctly applied, are efficient and cost effective; however, they are often incorrectly used. It is important to establish tick ecology and the epidemiology as a basis for choice of the fight against ticks and tick-borne diseases.

\subsection{Methodology}

\subsection{Study design and population}

The general objective of the study was to 'assess the causes of tick resistance to acaricides in treatment of cattle in Uganda, Kazo County in Kiruhura District. Specifically the study aimed at assessing the level of availability and affordability of acaricides by cattle farmers as well as the effectiveness of acaricides for tick control in cattle in Uganda. The study population comprised commercial and communal cattle farmers; staffs of Kiruhura District Veterinary Department (DVD); persons operating retail veterinary shops; suppliers and or importers of veterinary medicines; staffs of National Drug Authority (NDA); Ministry of Agriculture Animal Industries and Fisheries (MAAIF); and Staffs of Makerere University, College of Veterinary Medicines.

\section{2 sample size, sampling techniques, data collection methods and analysis}

The sample size of the study was drawn from the updated database of National Drug Authority (NDA) and comprised 20 veterinary drug shops in Kanoni Sub-county, two respondents from DVD, MAAIF, Makerere School of Veterinary Medicine, Importers of Veterinary Medicines and NDA respectively giving a total of 40. Purposive and systematic sampling techniques were used to identify persons with relevant information on the study and ensure different categories of potential respondents were well represented. 
Methods of data collection included questionnaires, interviews, observation and document review. Descriptive statistics and content analysis methods were used to analyse the data

\subsection{Results and Discussion}

\subsection{Limiting Factors and Choice of Acaricide for Tick Control}

The study observed that it is the desire of every cattle farmer to control ticks in their farms. The greatest challenge is that the acaricides in the market are not as effective and efficient for tick control as the farmers would expect. It was asserted that ticks have potential to multiply even faster if the most effective acaricide is not applied. Although there are quite a number of acaricides in the market, the farmer is faced with a challenge to choose the most efficacious acaricides. Given that the farmers are not technical; their choices are driven by expert advice from the veterinarians operating at the different selling points.

One of the major challenges is that all operators of agro-chemical dealers must have a list of Essential Drugs from the National Drug Authority but the situation was different on the ground where some operators did not have the lists at the time of interview as they could not produce them when asked. Those who had the lists claimed that the lists were not updated and some of the drugs therein were no longer relevant on the market. It was also established that as a result, some agro-chemical dealers stock drugs not on the list and go ahead to prescribe them for use on cattle treatment. In a situation where the agro-chemical dealers are not guided, it becomes hard for them to guide the farmers as each one of them prescribes an acaricide regime of choice sometimes minding less about the farmers' situation. Some agrochemical dealers are run by non-professionals simply because they are related to the owners. The challenge which farmers find also result from failure to tell whether advice sought is from qualified right persons. As a result, some farmers are forced to consult with fellow farmers on which acaricide worked well for them so that they could also apply. The recommendation may not be appreciated since the farm conditions may not necessarily be the same. These issues have contributed to tick resistance to acaricides

The study further revealed that some of the farmers consider prices of the acaricides as the basis for choice of what acaricide to apply. They end up going in for the cheap ones even when they are sure it is not effective. Where they choose to buy the recommended effective acaricides, it was revealed that dilution rations are not followed as prescribed. This is done in interest to use the same acaricides quite frequently and on a number of cattle. The consequence is that the burden of tick resistance continues to manifest on farms yet in the long run there is no saving done, cattle continuously fall sick and eventually die. This shows reduction in number of cattle sold for beef, reduction in quantities of milk produced, exposure to infected dairy products which in turn affect human hen impairing their potential to produce as an "economic animal'. Box 3.1 shows other results on factors infl oice of acaricide used by farmers is presented;

\section{Box 3.1: Factors influencing choice of acaricides}

- I know more syndrome - I have practiced cattle farming since I was born. I have experience and know what we normally use on the farm. Since I have the record and know the behaviour of cattle when they fall sick, I cannot go wrong.

- Depends on Efficacy of the acaricides based on advice from the veterinary doctors

- It depends on the prices since they are very many on the market and serves the same purpose, I buy the cheapest. The traders choose to ask you for any money they wish so I can't go giving away money just like that. Environmental/ weather conditions. During the dry season one may spray once a week but when it's rainy, you may be forced to do it twice a week which is costly.

- It depends on the mixing ratios. Some acaricides can be mixed in larger volumes of water and serve many animals as opposed to other acaricides with very low mixing ratios.

- I use trial and error method. I have used several acaricides but after a while they cease to be effective for tick control. Therefore, any recommended acaricide for as long as I have the money I can buy.

- The frequency of application. It is expensive if you buy an acaricides which requires you to apply several times a week. At least if application is once a week, I can afford to pay for it.

- There are situations where we face challenges of stock outs thus we are forced to buy what is available on the market. Besides, the drug shops are located in distant places from the farmers so some times for convenience we buy what is easily accessible.

- There is low willingness by businessmen and women to establish drug shop in the rural areas.

- Previous experience determines what acaricide I should use. There is no reason why I should go in for a new trade name when the old one has been effective.

- Vigorous advertisement by the sales team for the different dealers. Once sufficient information is given to me about the product then I can buy it at any shop for as long as I can afford the price. 


\subsection{Type of Acaricide Used}

The study established that the farmers in Kazo use a variety of acaricides for tick control in their farms. There are quite a number of registered dealers thus they strive to ensure that their products dominate the market. The acaricides on the market are inform of broad classes including amitraz, pyrethroids, combinations and organophosphates. Study results show that majority of farmers $45.4 \%$ use acaricides in the class of combinations followed by amitraz $34 \%$ as illustrated in Table 3.1.

Table 3.1: Type of Acaricide Used

\begin{tabular}{|l|l|l|}
\hline Type & Number & Percentage \\
\hline Organophosphate & 12 & 13.4 \\
\hline Amitraz & 30 & 34.0 \\
\hline Pyrethroids & 01 & 1.0 \\
\hline Combinations & 40 & 45.4 \\
\hline Others & 06 & 6.2 \\
\hline Total & $\mathbf{8 9}$ & $\mathbf{1 0 0 . 0}$ \\
\hline
\end{tabular}

Source: Field Data 2015

The acaricides under the different classes are further listed down in table 3.2 below and the factors that influence the farmers' choice of acaricide are already presented under sub section Box 3.1 respectively. When farmers are not consistent in use of the acaricides, the issue of resistance is enhanced and huge losses of livestock have been experienced in terms of high morbidity, mortality and low price demand in the market

Table 3.2: Acaricide Classes, Types, and Prices

\begin{tabular}{|l|l|l|l|l|l|l|l|}
\hline $\begin{array}{l}\text { Pyrethroids @ @ } \\
\text { Litre }\end{array}$ & $\begin{array}{l}\text { Price } \\
\text { (UGX) }\end{array}$ & $\begin{array}{l}\text { Combinations } \\
\text { @ Litre }\end{array}$ & $\begin{array}{l}\text { Price } \\
(\text { UGX) }\end{array}$ & $\begin{array}{l}\text { Amitraz } \\
\text { @ Litre }\end{array}$ & $\begin{array}{l}\text { Price } \\
(\text { UGX) }\end{array}$ & $\begin{array}{l}\text { Organophosphate } \\
\text { @ Liter }\end{array}$ & $\begin{array}{l}\text { Price } \\
(\text { UGX) }\end{array}$ \\
\hline Renegade & 65,000 & Prtaid & 68,000 & Milbitraz & 36,500 & Supona Extra & 100,000 \\
\hline . Sypertix & 69,878 & Duo-dip & 68,000 & Norotraz & 32,850 & & \\
\hline . Alphapor & 45,000 & & & Bimatraz & 28,500 & & \\
\hline Paracide & 65,000 & & & Bovitraz & 34,000 & & \\
\hline . Tsetse tick & & & & Almatix & 32,500 & & \\
\hline Cypermethrin & 41,000 & & & Amitix & 34,000 & & \\
\hline . Bayticol & 75,000 & & & Triatix & 48,000 & & \\
\hline Cyperguard & 80,000 & & & Taktik & 48,000 & & \\
\hline Vectocid & 73,000 & & & & & & \\
\hline Deltaguard & 75,000 & & & & & & \\
\hline
\end{tabular}

Source: Field Data 2015

\subsection{Rotation Period for Acaricide Application}

The different acaricides on the market are well labelled and have a manual which is intended to guide the farmer on the application and other detail regarding use of the acaricide. Among the instructions, farmers with reference to the manual are supposed to use the acaricide over a given period before changing to another. The reasons for applying different acaricides on a rotational basis is because ticks gain resistance as a result of adopting to the conditions of the acaricide used. To lower their resistance and wipe them out completely, change of acaricide is recommended to subject the ticks to a new environment. It takes time for the tick to adapt and gain resistance thus eradicating ticks requires the farmer to regularly rotate choices across the different acaricides as recommended by the veterenian.

Study results show that different farmers rotate across the available acaricides after a varied period without following the manual. Majority of the farmers (41.2\%) rotate after every one year as illustrated in table3.3 and therefore enhances chances of tick resistance

Table 3.3: Duration for Rotating across Acaricides

\begin{tabular}{|c|c|c|}
\hline Type & Number & Percentage \\
\hline Less than 1 year & 20 & 22.7 \\
\hline 1 Year & 37 & 41.2 \\
\hline 1-5 Years & 23 & 25.8 \\
\hline Over 5 Years & 09 & 10.3 \\
\hline Total & $\mathbf{8 9}$ & $\mathbf{1 0 0 . 0}$ \\
\hline
\end{tabular}

Source: Field Data 2015 
It was established that none of the farmers rotates across the acaricides as per recommendations by a veterinary and therefore increasing continued resistance of ticks to the acaricides. Although the farmers trust the efficacy of the acaricides, they observe that the same ticks survive and they breed new species of ticks with increased resistance. Results showed that for as long as there is continued infestation of cattle with ticks upon application of a given type of acaricide to alarming proportions, the farmers also change to another type without consulting veterinary officers. The duration is depended on the magnitude or level of infestation of cattle with ticks.

\subsection{Access to Veterinary Services}

Although Government under the Local Government Decentralization system provides for placement of a Veterinary Officer in each District, not all farmers have access to the Officers. Study results indicated that only $25.8 \%$ of the respondents have no access to a Veterinary Officer. Half (50\%), of those with access to the Veterinary Officer, $74.2 \%$ contended not getting the services needed from the Officer. Table 3.4 show the relationship between access to the Officer and getting the services as expected.

\section{Table 3.4: Relationship between Access to Veterinary Officer and Services}

\begin{tabular}{|l|l|l|l|l|}
\hline \multirow{2}{*}{ Response } & \multicolumn{2}{|l|}{ Access to Veterinary Officer } & \multicolumn{2}{l|}{ Access to Services Needed } \\
\cline { 2 - 5 } & Number & Percentage & Number & Percentage \\
\hline Yes & 72 & 74.2 & 36 & 50 \\
\hline No & 25 & 25.8 & 36 & 50 \\
\hline Total & $\mathbf{9 7}$ & $\mathbf{1 0 0 . 0}$ & $\mathbf{7 2}$ & $\mathbf{1 0 0 . 0}$ \\
\hline
\end{tabular}

Source: Field Data 2015

The Government staffing structure at District level provides for only one position of a Veterinary Officer who is not well facilitated to cover the entire District. The large scale cattle farmer are in the rural areas since this is where adequate land for farming could be accessed. On the contrary, the Veterinary Officers are located at the District headquarters in the urban areas and since they are not well facilitated, the services never reach to the intended beneficiaries. The services which would in any case be offered at free cost have serious financial implications on the farmer. The farmer has to pay for the services of the Government Officer who must be booked well in advance since there is a known schedule for his/ her movement. This in itself is a challenge since some of the farmers' concerns may be emergencies. Hiring services of private Veterinary officers is twice as expensive since the charges are negotiable and not regulated. The farmer is left with no option but to ensure that there is money to pay for veterinary services on the farm.

\subsection{Challenges of Accessing Acaricides and Veterinary Services}

Overall, the study results show that acaricides and other related veterinary services are available but the challenge lies in accessing them. Besides, even when you have access to the services, it was revealed ticks continue to infest cattle farms causing the farmer to routinely spend money on control of ticks. Meanwhile it is true that counterfeit acaricides exist on the market. Tick resistance to acaricides cannot wholly be blamed on the counterfeits. It is true that even the certified and efficacious acaricides have failed to completely kill the ticks.

The farmers on the other hand have no idea about identity of counterfeit acaricides thus risk losing a lot of money on counterfeits yet the certified acaricides are also too expensive. The farmers travel longer distances to buy acaricides and other farm supplies since they are in the rural areas yet the services they require/ agro-chemical shops are in the town centre. The agro-chemical shops which are closer to the farmer normally suffer from low stock. They lack variety and at the same time stock out is the order of business. This further supports the argument that farmers are forced to buy acaricides which are easily accessible to them. Veterinary consultancy services on the other hand are received from the attendants in the agro-chemical dealers of which the farmers only imagine they are professionals. There were also cases of non adherence to expert advice by the farmers since they have practiced cattle farming for longer periods of which the Consultant may not have the experience.

\subsection{Reasons for Failure to Control Ticks}

Ticks and tick borne diseases are a major constraint to livestock improvement in Kazo County. The effects of failed tick control to the farmers are quite a number including decrease in household income following decrease in cattle stock, production levels and quality of the animals. Farmers in the County have done everything possible to control ticks but the problem continues to present itself across all cattle farmers. Results of the questionnaire survey indicated that many participants (83.5\%) applied the acaricides weekly and perceived the use of acaricides as beneficial, despite citing economic constraints as the main reason for their reduced level of participation. Other farmers (15.5\%) revealed that application of acaricides on their farms is done after every two weeks, only $1 \%$ of the farmers apply on a monthly basis. Majority (72.2\%) of the participants contended that frequency of tick control on their farms was adequate. 
Nonetheless, efforts for tick control remain futile since the challenge of ticks on all cattle farms continue to manifest. Failure to control ticks in the farms is attributed to a number of reasons including: poor fencing of the farms which allows stray animals to penetrate and some farmers do communal farming; the cost of acaricide which is high compromises the frequency of application on the farms; laziness of some farmers who never clear the bush around their farms yet it harbors ticks; and failure to adhere to expert advice and instructions by some farmers. As a result, farmers end up using poor mixing ratios for acaricide dilution thus subjecting the cattle to substandard doses and subsequently leading to tick resistance to acaricides. It was revealed that counterfeit/ adulterated chemicals are also available in the market and used by some farmers thus enhancing the problem of resistance.

The importers and stockiest are mainly concerned about how much profit they can realize after supplying or selling their products. Consideration of efficacy standards of the products/ acaricides is secondary. In light of the inadequate regulatory framework, adulterated acaricides are smuggled into the local market thus cannot be effective for tick control. Farmers were also found not to seek advice from the professional veterinarians for they assume they are knowledgeable since they have practiced cattle farming for long. Besides they are also afraid of incurring the cost of consultation fees. The farmers also make poor choices of tick control methods and sometimes even apply the methods chosen wrongly. The sites loved by the ticks are known but the farmer may not concentrate on spraying these sites which influences tick resistance.

The results further show that farmers keep changing the acaricides used on the farms thus within a short period, many different acaricides are found on a single farm at the same time. This makes it easy for the surviving ticks to adapt to such an environment and become resistant.

\subsection{Measures for Tick Control}

The survey established that there are various initiatives that farmers have undertaken to adequately control ticks on their farms. The most frequent response as per study findings was fencing of the cattle farms (24\%) followed by application of acaricides (21\%). Respondents revealed that there are many vectors which they need to guard against since they can enter their farms while carrying ticks. Animals like goats, sheep, and dogs were mentioned as the biggest threat since they can easily cross through the fence and mix with the cattle. The control of ticks by application of acaricides on cattle in a fence can never be effective where untreated animals are free to stray into the farm.

The poor farming practices by some farmers make it very expensive on the part of others who make time to invest in tick control. Part of the acaricides used for tick control may spill on the land especially where the method used is of spraying. Where the method is of dipping, disposing of the dip water is also done on land thus with time concentration of chemical affects the quality and structure of the soil. Although acaricide use is the most recommended, it may have economic implications if efficacy and safety standards are not complied with.

Other efforts for tick control on farms included: attending training workshops and seminars to acquire knowledge and skills; bush clearing; consultation with veterinary professionals; and farm visits by the Local Government veterinary extension workers. Results showed that farmers have also started the practice of vaccinating $(1.5 \%)$ the cattle to boost their immunity against contracting tick borne diseases as presented in table 3.5 below.

Table 3.5: Tick Control Measures

\begin{tabular}{|l|l|l|}
\hline Response & Frequency & Percentage \\
\hline Apply acaricide & 67 & 22 \\
\hline Training & 32 & 10 \\
\hline Bush Clearing & 67 & 21 \\
\hline Consultation & 50 & 15 \\
\hline Farm Fencing & 78 & 24 \\
\hline Extension works & 20 & 6.2 \\
\hline Vaccination & 5 & 1.8 \\
\hline Total & $\mathbf{3 1 9}$ & $\mathbf{1 0 0 . 0}$ \\
\hline
\end{tabular}

Source: Field Data 2015

\subsection{Affordability of Acaricides}

Overall, the study results indicated that the prices of acaricides are high (74\%). Nonetheless, the farmers added that they have no choice and continue to buy the same chemicals. The cost of controlling ticks and tick borne diseases in cattle is as twice cheaper than the cost of death of cattle. Cattle are a source of income for many cattle keeping households resulting from sale of the cattle and related products like milk and beef. 
The cattle farmers are able to raise school fees for their children, pay bride price, and meet household health needs among others. This however, is not the reason for keeping the prices of acaricides high. Study results from key informant interviews further revealed that the farmers should be in a position to afford buying acaricides and pay for any other farm support services especially where a cattle rearing is looked at as an enterprise (cattle for dairy or ranch). The farmers who may not afford should be those keeping small numbers of less than five cattle. On the part of importers, results showed that the cost of registering a product/ acaricide and keeping it on the register is too expensive. A minimum of 500 US Dollar is required annually to keep the product on the register. This is the reason why the agrochemical dealers are facing challenges of stock outs on some products. It is demand that drives business thus money is spent on products which have a higher sales turn over from a business angle.

The manufacturers of acaricides are also very few in number which prompts dealers to procure acaricides locally from the importers which is also expensive. Procuring the products from the manufacturer fetches a higher profit margin as opposed to procuring from the importer. Each product has a supplier and if the manufacturer is not a supplier of the importer then it becomes difficult to procure their product. Table 3.6 below present comments given by respondents on acaricide prices.

Table 3.6: Comments on Prices of Acaricides

\begin{tabular}{|l|l|l|}
\hline Comment & Number & Percentage \\
\hline Affordable & 12 & 10 \\
\hline Expensive & 86 & 74 \\
\hline Fluctuation of prices & 12 & 10 \\
\hline No comment & 07 & 6 \\
\hline Total & $\mathbf{1 1 7}$ & $\mathbf{1 0 0}$ \\
\hline
\end{tabular}

Source: Field Data 2015

\subsection{Regulation of Quality of Acaricides}

Regulation of quality and efficacy of veterinary medicines in Uganda is a function of Government and it's done through the National Drug Authority (NDA). Study results indicate that the function has not been effectively executed. The feeling is that NDA focused on regulation of manufacturer, importer and forgets about the agro-chemical dealers yet these are the key contact point for the end user who is the farmer. Some of the acaricides and drugs are sold over the counter against the recommended practice and the farmer is left to administer them. By law/ in practice, the veterinary officers are supposed to be stationed at the agro-chemical shops and must cover at least two shops. This is not observed and there are either no or inadequate efforts to ensure compliance.

\subsubsection{Satisfaction with Quality of Acaricides}

The study established that $65 \%$ of the farmers are satisfied with the quality of acaricides available on the market although majority $(68 \%)$ cannot differentiate the certified quality acaricides from the counterfeits as illustrated in table 3.7. below.

Table 3.7: Relationship between Satisfaction and Differentiation of Acaricide Quality

\begin{tabular}{|l|l|l|l|l|}
\hline \multirow{2}{*}{ Comment } & Satisfaction & Differentiation \\
\cline { 2 - 5 } & Number & Percentage & Number & Percentage \\
\hline Yes & 58 & 65.0 & 28 & 32 \\
\hline No & 31 & 35.0 & 61 & 68 \\
\hline Total & $\mathbf{8 9}$ & $\mathbf{1 0 0 . 0}$ & $\mathbf{8 9}$ & $\mathbf{1 0 0}$ \\
\hline
\end{tabular}

Source: Field Data 2015

The study results show that although the farmers are not able to differentiate the good quality acaricides from counterfeits, they are satisfied with the quality of the acaricides they use. The reason for such a response is in light of the fact that majority (65\%) are able to see reduction of cattle infestation with ticks on their farms. The farmers are contented that even if the acaricides used kills the ticks, effectiveness can never be $100 \%$. There are always a few ticks that resist and breed thereafter.

In the case of farmers who are able to differentiate the acaricides (32\%), they are in a position to tell from the colour changes and smell upon dilution/ mixing the acaricides. On the other hand, it was revealed that the cattle normally present signs of having contracted East Coast Fever (ECF). The manufacturers' instructions and labels are known to the farmers and they can tell after careful reading of the labels and instructions. 


\subsubsection{Adherence to Available Regulation}

Regarding availability of regulations on use of acaricides, the majority of the participants $(84.5 \%)$ were aware of existence of laws. Results indicate non-adherence to the laws at $77.3 \%$ which further reveals a weakness on the part of NDA to enforce the laws. The gap was observed to be more at the farm, distribution and importation levels. Table 3.8 below present the opinions of the participants regarding existence of laws and adherence thereof;

Table 3.8: Relationship between Existing Laws and Adherence

\begin{tabular}{|l|l|l|l|l|}
\hline \multirow{2}{*}{ Comment } & \multicolumn{3}{|l|}{ Laws in Place } & Adherence \\
\cline { 2 - 5 } & Number & Percentage & Number & Percentage \\
\hline Yes & 99 & 84.5 & 27 & 22.7 \\
\hline No & 18 & 15.5 & 90 & 77.3 \\
\hline Total & $\mathbf{1 1 7}$ & $\mathbf{1 0 0 . 0}$ & $\mathbf{1 1 7}$ & $\mathbf{1 0 0}$ \\
\hline
\end{tabular}

Source: Field Data 2015

To a large extent $77.3 \%$, non-adherence to the laws was observed following experiences where concern is raised by farmers and NDA never comes out to find solutions. There is no feedback given to farmers regarding issues affecting them. The drugs are accessed through agents but they are not well monitored. It is assumed that such odds are responsible for continued existence of adulterated drugs on the market. The borders are porous in that there are restrictions of trafficking animals without license but often time cattle is driven in and out of the County to other places and markets. The way animals are trafficked without interruption is the same way acaricides are brought on the market. Some of the farmers are illiterate but NDA has never impressed upon the veterinary officers to explain to the farmers as a mandatory practice.

The staffing of NDA is too thin to monitor veterinary practices across the country. This is why many ill practices go unnoticed. There is a challenge of stock outs in the agro-chemical dealers but NDA does not follow up to establish what drugs on the Essential Drug List (EDL) are out of stock. The EDL has not been updated in a long time thus the stockists are at large to stock what their clients demand for. It was also observed that the dilutions indicated on some acaricide packs don't tally to what is in the EDL. Some drugs which were phased out continue to appear in the current copy of EDL.

Concerning efforts made by NDA to ensure compliance to the laws, results show that NDA verifies and clears licenses of owners of drug facilities. Respondents could vividly recall experiences where some drug shops were closed for noncompliance with the laws. The supervision is done but not regularly which leaves gaps for ill practices.

\subsubsection{Effect of Counterfeit Acaricides}

Most of the farmers agreed that counterfeit acaricides exist on the market. This is a result of the inadequate regulation, leaving the farmers susceptible to all likely effects. The first effect is such that the farmer administers the acaricide and results are negative. The farmers lose time and pay twice as they have to buy new acaricides to treat the animals. The other effects of use of counterfeit acaricides are presented in the Box 3.2.

\section{Box 3.2: Effect of Counterfeit Acaricides}

- The cattle falls sick and die which reduces the stock on the farm.

- Once counterfeits are applied, the cattle lose weight and develop lumpy skin.

- The farmer is forced to sell off the sick cattle which fetch little money. Expected farm income reduces.

- The ticks never die so there remains a challenge of continued infestation of cattle with ticks. Tick gain more immunity and resistance to even the good quality acaricides.

- The production level of cattle goes down. A cow may end up reducing the quantity of milk produce by about $50 \%$.

- Contribution of the Cattle towards the Gross Domestic Product - GDP goes down. 


\subsection{Addressing Challenges of Tick Resistance to Acaricides}

The factors that influence continued tick resistance in Kazo County and across cattle farmers in Uganda cannot be addressed by a single solution. To start with, it is important that the regulatory framework is in place or enhanced since implementation of other solutions becomes very easy when operating within the law. The study has established that acaricides are in place and farmers can afford to buy them. This should be followed by Good Agricultural Practices by all farmers if the tick resistance challenge is to be completely ameliorated.

The results suggested that all veterinary drug outlets should be managed by a veterinary professional. Many drug or farm shops are managed as family shops where a professional may leave his/ her spouse (not professional) to attend to the farmers' concerns. Farmers should adhere to dilution levels of chemicals as per instructions from the manufactures since over dozes may kill the cattle. The beef and dairy products may be contaminated as well. The regulation of use of acaricides at farm level should as well involve professionals to advise, and sensitize the farmers on application procedure since some of them may be illiterate thus unable to comprehend instructions on the acaricides packs.

It was also proposed that MAAIF establishes and recruits a tick control officer per district to work with the Veterinary Officers. The NDA on the other hand should scale up its staff numbers since their staffs are few compared with the scope of work to be done. Further still, Government should reinstate the practice of zoning the different regions where farmers' concerns are addressed from a regional perspective. For instance, acaricides would be rotated on a regional basis such that farmers in one region use the same acaricide at the same time. Should the acaricide fail in one region then it's taken to another and a new one recommended for that region.

It is important that the professionals are regulated in addition to the chemicals to allow for questioning in event of any errors. Some of the practitioners make errors/ mistakes on the farms of the farmer which are very costly and the farmer has no fallback position. There should be an open door for the farmers to report practitioners to the Veterinary Board to answer questions regarding their recommendations. Although the Board exists, farmers are not aware of its function. Awareness creation is important to the farmers such that they know what to do and were to seek help whenever they have issues. The Board should go on ground to also supervise and monitor farming practices as well as the Veterinarians. Respondents suggested proper handling of the chemicals starting with the manufacturers premise downwards in terms of storage and transportation. This will ensure that efficacy standards are not watered down. The farmers on the farm should also ensure that the chemicals are kept safely under lock and key since they are harmful and poisonous. The veterinarians work with poisons and as such careful handling of drugs should be emphasized.

\subsection{Conclusion}

The study concludes that a lot of effort should be geared towards streamlining the available laws and policies under which the farmers operated. The laws are inadequate and as such adherence is lacking. Efficacy levels for the chemicals should be stepped high such that even if there may be a gap, the farmer never fall victim of using counterfeits. Participants are aware that counterfeits exist on the market and this is largely a result of the inadequate regulatory environment.

There is no much complaint about the acaricides in place and the regimes followed. However, this does not mean that they are effective since there is evidence of death of the ticks but it is also true, other ticks are resistant so they survive. There are new resistant species which further research should target and appropriate acaricides recommended. Results showed that farmers rotated from acaricide to another and all asserted that the acaricides can kill the ticks ( $45.4 \%$ of the farmers were found using acaricides in the class of combinations while others (34\%) used amitraz)

Majority of the farmers (84.5\%) can afford buying the chemicals they require on their farms despite the assertion that the chemicals/ acaricides are expensive (79.4\%). On the other hand having access to a veterinary officer is not the solution to ending tick resistance. Results showed that only $25.8 \%$ lack access to a veterinary officer but then $50 \%$ of those farmers with access never received the services they expected from the officers.

Frequency of administering the acaricides is dependent on manufacturers' instructions but farmers fault on routines following the level of infestation of cattle with tick. Majority of the farmers (72.2\%) applied the acaricides on a weekly basis and find it adequate however, none of them consented not to face ticks as a challenge on their farms.

\subsection{Policy recommendations}

a) The government should consider reviewing and updating the Essential Drug List to ensure that only the appropriate drugs/ chemicals are there. The phased out drugs on the list should be removed. Prescriptions for the new drugs should be clear since failure to update will mean prescribing chemicals based on wrong information. Adherence should also be emphasized on the part of pharmacists to the farmer since the veterinary drugs can be poisonous if not handled under minimum safe. 
b) The Veterinary officers should be equipped with the necessary logistics to monitor the tick infestation in cattle and other animals. Change of the acaricides should be recommended as soon as notice for resistance of one acaricide is made. The change of acaricide should be accompanied by proper use of the chemicals as per manufacturers' instructions.

c) Legislation to curb unlicensed trafficking of animals should be enforced. Although the borders are porous, the NDA surveillance team should be facilitated to do monitoring across country. This should be done to the cattle entering or leaving one farm for another to ensure that the cattle are free of ticks and TBDs. The same should be done for cattle moved to abattoirs especially to ensure that beef is safe for consumption.

d) The challenge of ticks should not only be addressed by targeting the big farmers. Even the farmers of less than five animals should be targeted. They may not invest in cattle keeping as an enterprise but since they have the cattle their poor farming practices may end up victimizing the bigger farmers. Government should devise financing mechanisms geared towards enabling all farmers to access veterinary services by urging then to form farmer groups. The farmer groups can easily access financing from loaning companies as opposed to an individual farmer.

For further research, the study recommends that scientific laboratory research be carried out to establish the biological construct of the different tick species in the Ugandan environment. The research should as well focus to establish the development of tick resistance to the acaricides in use. It was found out that tick die but some survive, breed and multiply at a faster rate. It is important that different tick species are targeted differently. Across the acaricides in the market, results showed that no acaricides has $100 \%$ kill for ticks. New acaricides with new modes of action should be developed through research and development.

\subsection{References}

Andrew, Y. L.; Andrew C.; Chen, R.Miller, R. Davey B .and John, E .G. (2007). Acaricide resistance and synergism between Permethrin and amitraz against susceptible and resistant strains of Boophilusmicroplus (Acari: Ixodidae). Pest ManagSci63:882-889.

Anonymous (1984a). Ecological principles in tick control. In Ticks and Tick-borne Disease Control. A Practical Field Manual. Vol. 1 Tick Control, pp. 188-245. Food and Agriculture Organization, Rome, Italy.

Bram, R.A. 1975. Tick-borne livestock diseases and their vectors. 1. The global problem. Wild Anim. Rev., 16: 1-5.

Callow, L.L. 1975. Tick-borne livestock diseases and their vectors. 3. Australian methods of vaccination against anaplasmosis and babesiosis. Wild Anim. Rev., 18: 9-15.

Callow, L.L. 1978. Ticks and tick-borne diseases as a barrier to the introduction of exotic cattle to the tropics. Wld Anim. Rev., 28: 20-25.

Cisak E, Zajac V,Wójcik-Fatla A, Dutkiewicz J. Risk of tick-borne diseases in various categories of employment among forestry workers in eastern Poland. Ann Agric Environ Med 2012; 19:469-474.

Drummond RO. (1983) Tick-borne livestock diseases and their vectors. Chemical control of ticks. Wld Anim Rev36:28-33.

Drummond, R.O., Bram, R.A. \&Konnerup, N. 1978. Animal pests and world food production. In: Pimentel, D., World food, pest losses, and the environment. AAAS Symposium, 13: 63-93.

Holden S (1999): The economy of delivery of veterinary services. Revue Scientifique (International Office of Epizootics), Volume18:425-439.

Koney, E.B.M (2004). Livestock production and health in Ghana. 2nd edition. Advent Press, Accra: 4-21.

McCosker, P. J. (1979). Global aspects of the management and control of ticks of veterinary importance. In Recent Advances in Acarology (ed. Rodriguez, J.) 2, pp. 45-53.New York, Academic Press.

McLeod, R.S., Boreham, P.F.L. (ed.) \&Boreham R.E. (1995). Costs of major parasites to the Australian livestock industries. International Journal for Parasitology, 25(11): 1363-1367.

Mkonyi, P.A. (1985). "Theileriosis in Mainland Tanzania". In Irvin, A.D. Immunization against Theileriosis in Africa. Nairobi; International Laboratory for Research on Animal Diseases.

National Drug Authority (1993) National Drug Policy and Act. Ministry of Health, Kampala Uganda.

National Veterinary Drug Policy (2002) The National Veterinary Drug Policy. Ministry of Agricultural, Animal Industry and Fisheries. Entebbe Uganda.

Okello-Onen J., Ssekitto C.M.B., Ssentongo Y.K. and Kudamba C.A.L. (1992) Tick situation and control strategies in Uganda. Insect Science Application 13(4):657-660.

Owens, (2003) Animal health products distributions- a study of Kenya, Uganda and South Africa. AU-IBAR, PACE program, Nairobi, Kenya. 
Rivero, A., Vézilier, J., Weill, M., Read, A. F. and Gandon, S. (2010) Insecticide control of vector-borne diseases: when is insecticide resistance a problem? Public Library of Science, Pathogens, 6, e1001000.

Rwamirama, B., Ruhakana, R. Sematiko, G., and Vudriko, P (2014); Presidential Directive to the Relevant Government Organs to Fast Track the "War" against Ticks. Ministry of Agriculture Animal Industry and Fisheries, National Drug Authority (NDA), Ministry of Health and Makerere University College of Veterinary Medicine held in Kampala.

Samaanya JP, Semambo DK, Nakimbugwe H, Mubiru J, Busuulwa H,Ndumu D (2002). The Farm Animal Genetic Resources Fact Sheet for Uganda.

SNV (June 2013), Acaricide resistance in ticks causing cattle disease in Uganda.

Taracha, E. and Taylor, D. (2005). Integrated Control of East Coast Fever in Cattle of Small-holder Farmers. Nairobi; International Livestock Research Institute.

Whitehead.G.B (1973). Resistance to Acaricides in Ticks Eastern Cape Province. S. Afr. Med. J., 47: 342. 